\title{
Complexities of Species Co-Existence within Modern, Urbanized Landscapes
}

\author{
Erin C McCance ${ }^{1 *}$ and Richard K Baydack ${ }^{2}$ \\ 1,2EcoLogic Environmental Inc, Canada \\ *Corresponding author: Erin C McCance, EcoLogic Environmental Inc Waterford Bay, Winnipeg, Manitoba, R3T 1H5, Canada
}

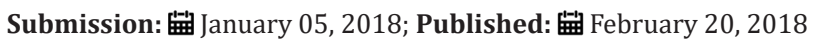

\section{Introduction}

During the latter half of the twentieth century, human population growth and urbanization resulted in significant changes in human occupancy of the landscape, re-shaping the global footprint, and creating new ecological spaces. Although these human induced land-use changes are relatively recent, they are occurring at a rapid rate, leaving humans and wildlife to compete, more than ever before, for available space and resources. Ecologists have Primarily studied species populations and communities in non-urban environments and have largely avoided the urbanized world [1]. For many species, urban environments offer numerous benefits and although human development has certainly encroached on wildlife habitats, many wildlife species have realized the benefits present within urban environments, and have encroached right back [2], defining a new way of living for both human and wildlife species. The urban-wild land boundary has now become increasingly obscure. Within these city spaces, urbanites have complex and shifting views on how to adapt to their new 'neighbours". The resulting dynamics between humans and wildlife have never been more "confused, complicated, and conflicted" [2]. Managers called upon to reduce human-wildlife conflict in urban areas find themselves within an arena of competing interests as they face the ecological and social dynamics associated with urban wildlife management.

The past sixty plus years represent a time when First World societies underwent a transition from rural, agricultural, to urban lifestyles [3]. Population growth and capitalization, coupled with the influx of people into urban centers, have stretched city limits and created infrastructure in previously natural, undeveloped habitat. Currently there are twenty cities worldwide that have human populations over 20 million people compared to just two cities of this size in the 1950s [1]. Many metropolis areas are not defined by a single city center but rather from a series of extended suburban areas, one connecting to another, bleeding out across the landscape, and creating what Gillham defines as "the limitless City" [4]. Hand-in-hand with increasing human populations and urbanization are all the associated decisions made with respect to land-development and infrastructure influenced by job markets, real-estate, house-hold preference, highway placement, among other variables [1]. As a result of these human induced interrelated land-use changes, the landscape is increasingly shaped by extensive fragmentation of habitat, which is one of this century's most substantial threats to wildlife populations and biodiversity [5]. Without question, urbanization and its associated development shape the global footprint more than ever before with the earth's ecosystems increasing influenced by the rate and pattern of urban growth [1].

As Jennifer Wolch contends there is a mainstream theory that urbanization transforms "empty" land through the process of "development" to produce "improved" land, a movement toward the "highest and best use" of space [6]. She points out, however, that this transformation is not of "empty" space at all, but of wild lands that are teeming with non-human life. These human induced land-use changes result in massive ecological destruction and a denaturalization of the environment such that the resulting landscapes are characterized by impoverished soil quality, drainage, and vegetation. Urban ecology is often dominated by invasive species, in systems that are out of balance as some species are welcome while other species such as predators, considered intolerable, are excluded. Wolch argues that human practices have altered the global environment as never before [6]. Wildlife managers, among others, who regard the extreme conversion of these "empty spaces" and overall biodiversity loss as intolerable, must confront the phenomenon of contemporary urbanization.

Coupled with these human induced transformations of the landscape from un-developed to developed spaces are the specific spatial orderings that humans have with respect to animals, situating them as either "in or out of place". These human constructed spatial orderings of animal geography situate wild animals in relation to space, place, environment, and landscape positioning them within the traditional geographic boundaries humans have established with relation to the "proper" places animals should physically occupy [6-11]. Given our current concerns for environmental integrity, environmental ethics, and reconnection with nature, the relationship between humans and animals is a complex, multi-dimensional issue. 
More than ever before, scholars are deconstructing these spatial orderings and challenging the wild/domestic dichotomy [12], along with conventional notions of inclusion and exclusion [13] these investigations into human-animal relations have given rise to new terms of reference such as anthrozoology, zoopolis [6], zoontologies [14], zoographies [15] and to the study of urban animal ecology. Given the rapid rate of human population growth and urbanization that occurred in the twentieth century, the importance of entertaining the notion of "letting animals back in" [6], is becoming apparent, this along with opening ourselves to the idea of urban "shared spaces" designed for species co-existence $[6,7,16]$. In aiming for this, however, wildlife management, in this new urban arena, must lend itself to the process of articulating management objectives and actions that consider perspectives across multiple disciplines and involve stakeholders at all levels of management action. Such considerations have implications for "ecological" and "social" carrying capacity. Urban ecosystems that are "out of balance" due to the human exclusion of predatory species function differently and as such, face challenges when those species populations that we consider to be tolerable grow and become overpopulated. As urban residents create backyard islands of habitat in an attempt to imitate nature and draw in wildlife, often in alarming numbers, the degree to which the urban ecological system is out of whack quickly becomes apparent. Generalist species thrive in these urban environments, stripped of their natural predators and often growing to overabundance.

Given the inter-related changes brought on by human population growth, urban sprawl, habitat modification, fragmentation, the creation of "enhanced ecosystems", and changing public attitudes and uses of wildlife, human-wildlife conflict has increased in urban areas. The increase in humanwildlife conflict is world-wide both in frequency and in severity given humans and wildlife are progressively forced to compete for space and resources [17]. Human and wildlife shared need for space, resource use, and habitat inevitably leads to humanwildlife conflict, since it is impossible for all members of a geographic community to have all of their needs met in exactly the same geographical place [11]. This is especially true, Lynn argues, of growing urban environments, resulting in shrinking wild land spaces necessary to sustain herds of herbivores and large carnivores and the essential associated biodiversity [11]. As urbanites become aware of the various downfallssuch as property damage, vehicle collisions, and Lyme disease transmission -that accompany living in close proximity to wildlife they call on wildlife managers to reduce human-wildlife conflict. Urban species co-existence is quickly replaced by a municipal battlefield, depicted by combat between both human and animal, while equally so, between human neighbors.

The end result is a community "at war" [2]. Residents experiencing human-wild life conflicts who feel the need to take matters into their own hands often leads to frustration, emotionally charged positions between residents, and further exacerbation of an already sensitive issue. Quickly, a majestic and valued species becomes reduced to nothing more than descriptive terms such as "pest", "nuisance", or "problem" wildlife. As various scholars begin to deconstruct the spatial orderings and the traditional boundaries humans have constructed with respect to animals occupying the landscape; the body of work on human-animal relations expands; and landscape architects creatively re-think spaces designed for species co-existence there is a fundamental and imperative need to bridge the gap between the notions of species co-existence and urban wildlife management. Further researched aimed at developing a framework which facilitates collaboration and a synthesis of knowledge and translates into practical and feasible species and land management is critically important.

\section{References}

1. Alberti, Marina (2008) Advances in urban ecology: integrating humans and ecological processes in urban ecosystems. University of Washington, USA.

2. Sterba, J (2012) Nature wars. Crown Publishers, New York, USA.

3. Clark AE, Kieran JL, Sara (2006) Urban wildlife management. CRC Press, New York, USA, pp.569.

4. Gillham, Oliver (2002) The limitless city, a primer on the urban sprawl debate, Island Press, Washington DC, USA.

5. Wilcox BA, Murphy DD (1985) Conservation strategy: the effects of fragmentation on extinction. The American Naturalist 125(6): 879-887.

6. Gullo, Andrea, Unna Lassiter, Jennifer Wolch (1998) The cougar's tale. In: Jennifer W, Jody E (Eds.), animal geographies: place, politics and identity in the nature-culture borderlands. Verso, London, UK, pp. 139-161.

7. Jones, Owain (2000) Ethical Geographies of human-non-human relations: encounters, collectives and spaces. In: Chris P, Chris W (Eds.), Animal spaces, beastly places: new geographies of human-animal relations. Routledge, New York, USA, pp. 268-291.

8. Wolch, Jennifer, Alec B, Unna L (2000) Constructing the animals worlds of inner-city los angeles. In: animal spaces, beastly places; new geographies of human-animal relations, Routledge, New York, USA, pp. 71-97.

9. Brownlow, Alec (2000) A wolf in the garden: ideology and change in the adirondack landscape. Chris P, Chris W (Eds.), Animal spaces, beastly places. Routledge Press, London, UK, pp. 141-158.

10. Emel, J, Jennifer W (1998) Witnessing the animal movement. In: Jennifer W, Jody E (Eds.), animal geographies: place, politics and identity in the nature-culture borderlands, Verso, UK, pp. 1-26.

11. Philo, Chris (1998) Animals, geography, and the city: notes on inclusion and exclusion. In: Wolch, Jody E (Eds.), animal geographies: place, politics and identity in the nature-culture borderlands.Verso, London, UK, pp. 51-71.

12. Clement, Grace (2007) The ethic of care and the problem of wild animals. In: Josephine D, Carol JA (Eds.), The feminist care tradition. Columbia University Press, New York, USA, pp. 301-315.

13. Lynn, William (1998) "Animals, ethics and geography." In: Jennifer W, Jody E (Eds.), Animal geographies: place, politics and identity in the nature-culture borderlands. Verso, London, UK, pp. 281-298.

14.Wolfe, Cary (2008) Thinking other-wise. Cognitive science, deconstruction and the (non) speaking (non) human subject. In: Jodey C, Waterloo (Eds.), Animal subjects: an ethical reader in a posthuman world (edn). Wilfrid Laurier University Press, Canada, pp.125-143.

15. Matthew C (2008) Zoographies: the question of the animal from heidegger to derrida. Columbia University Press, New York, USA, pp. 184. 
16. Philo C, Chris W (2010) Animal spaces, beastly places: an introduction. in animal spaces, beastly places: new geographies of human-animal relations. Routledge, London, UK, pp. 1-34.

\section{(c) (1) Creative Commons Attribution 4.0 BY International License}

For possible submissions Click Here
17. Madden, Francine (2009) Creating coexistence between humans and wildlife: global perspectives on local efforts to address human-wildlife conflict. Human Dimensions of Wildlife 9: 247-257.

\section{Your subsequent submission with Crimson Publishers} will attain the below benefits

- High-level peer review and editorial services

- Freely accessible online immediately upon publication

- Authors retain the copyright to their work

- Licensing it under a Creative Commons license

- Visibility through different online platforms

- Global attainment for your research

- Article availability in different formats (Pdf, E-pub, Full Text)

- Endless customer service

- Reasonable Membership services

- Reprints availability upon request

- One step article tracking system 